Cristine Vieira ${ }^{1,2}$

Nilson do Rosário Costa ${ }^{1}$

\title{
Estratégia profissional e mimetismo empresarial: os planos de saúde odontológicos no Brasil
}

\author{
Professional strategy and institutional isomorphism: \\ the dental health insurance industry in Brazil
}

${ }^{1}$ Escola N acional de Saúde Pública, Fiocruz. Rua Leopoldo Bulhões 1480, M anguinhos. 21041-210 Rio deJaneiro RJ. cristinevieira@ensp.fiocruz.br

${ }^{2}$ Escola de Odontologia, Universidade do Grande Rio.
Abstract This article analyzes theorganizational model of the dental health industry. The main organizational leaders in this industry are the professional cooperatives and group dental insurance companies. The theoretical basis of the article is theorganizational theory developed by $\mathrm{Di}$ M aggio and Powell. The dental health industry consists of a great number of small and very dynamic companies, however an expressive part of clientsand profit are concentrated in a few large companies. The results show that the industry has expanded the number of clients after the creation of the National Health Insurance Agency. The regulation re gime has forced institutional changes in the firms with regard to the market entry, permanence or exit patterns. There was no evidence that the regulatory rules have interfered with the development and financial conditions of theindustry. The average profitability of the sector, especially among thegroup dental insurancecompanies, is extremely high.

Key words Private health insurance, Dentistry service, Professionalism, Regulatory regime, Access
Resumo 0 artigo analisa o modelo organizacional das empresas de planos de saúde odontológicos das modalidades de cooperativas de profissionaise a odontologia de grupo para compreender a dinâmica da oferta de serviços odontológicos no país. Adotou-se como referência a formulação institucionalista de Di Maggio e Powell. 0 mercado de planos de saúde odontológico é pulverizado, com o predomínio de empresas de pequeno porte, eapresenta um grande dinamismo, que favorece as empresas de pequeno, médio e alto porte. As modalidades analisadas concentram a maior proporção de beneficiários e receitas. A análise geral do desempenho do setor revela impressionante dinamismo na captação de clientes, mesmo após a criação da ANS. 0 regime de regulação tem imposto um novo padrão institucional à entrada, permanência esaída das em presas no mercado, quenão afeta o desempenho setorial. Os dados analisados evidenciam que o setor de planos de saúde odontológicoséaltamenterentável, apresentando uma grande capacidade na geração de receitas que explica 0 crescimento e a permanência destas modalidades no mercado. Os padrões de rentabilidade média, principalmentedasempresas deodontologia degrupo, são extremamenteel evados, ficando muito acima de qualquer atividade empresarial do Brasil. Palavras-chave Planos privados de saúde, Serviços odontológicos, Profissionalismo, Regi me regulatório, Acesso 
Introdução

O objetivo deste artigo é descrever o modelo organizacional e analisar comparativamente as empresas de planos de saúde odontológicos das modalidades de cooperativas de profissionais ea odontologia de grupo.

0 mercado de planos privados de assistência à saúde tem sido bastante discutido nos últimos anos no Brasil. Apesar da criação de um sistema de saúde com acesso universal, tem ocorrido o crescimento do número de indivíduos com planos privados de saúde. 0 acesso a esses planos tem sido desigual entre as regiões metropolitanas brasileiras. Segundo os dados da Pesquisa Nacional por Amostra deD omicílios (PNAD) de 1998, realizada pelo IBGE, os estados deSão PauIo, Rio de Janeiro, M inas Gerais e Rio Grande do Sul concentravam $65 \%$ de todos os beneficiários do país ${ }^{1}$. A PNAD estimou para 1998 que 38,7 milhões de brasileiros eram beneficiários de planos privados de assi stência à saúde, sendo a distribuição geográfica dessa população extremamente concentrada na zona urbana $(95 \%)^{2}$.

Cinco anos depois, em 2003, a PNAD estimou em 43,2 milhões o número de brasileiros cobertos por pelo menos um plano de saúde, o que correspondia a $24,6 \%$ da população do país. Destes, 34,2 milhões de pessoas (79,2\%) estavam vinculados a planos de saúde privado, individual ou coletivo. Os restantes, 9 milhões de pessoas $(20,8 \%)$, estavam cobertos por planos de instituição de assistência ao servidor público (municipal, estadual ou militar). Outro dado relevante é que 0 acesso ao mercado de planos de saúde está condicionado à renda das famílias ${ }^{3}$.

O mercado de planos odontológicostem crescido em paralelo ao mercado de planos de saúde, embora os estudos sobre o setor odontológico dêem pouca atenção à presença e desempenho destas empresas no mercado. Por exemplo, publicação recente sobre saúde bucal não faz uma menção sequer à crescente inserção dessas empresas na oferta de serviços odontológicos4.

Algumas variáveis estruturais explicam a dinâmica eo crescimento do mercado de planos de saúde odontológico no Brasil. Dentre elas, destacam-se: a mudança no perfil profissional e da profissão odontológica, o sofrível acesso da população aos serviços de saúde bucal, o baixo gasto das famílias com despesas por desembolso direto para a assistência odontológica e o significativo peso dos gastos com planos privados de assistência à saúde.

A baixa sustentabilidade econômica do modelo liberal da profissão, representado por con- sultórios particulares, tem levado a profissão dos dentistas a criar mecanismos de permanência no mercado ${ }^{5}$. A economia das profissões liberais é condicionada pelo monopólio de competência, autonomia financeira e controle da clientela. A crise do modelo liberal vem promovendo alterações profundas no exercício profissional da odontologia. N ovas estratégias têm sido criadas na organização da oferta de serviços, buscando-se modelos associativos ou empresariais na tentativa de permanência no mercado.

\section{A dinâmica profissional}

O mercado de planos de saúde odontológicos tem crescido não só por uma questão empresarial, mas também é condicionado por uma estratégia dos profissionais da classe odontológica na tentativa de permanecerem inseridos no mercado, mantendo autonomia e acesso ao financiamento direto dos clientes.

A oferta de cirurgiões-dentistas é ampliada anualmente em ritmo superior ao do aumento da população geral: 0 índice dentistas/ 10.000 habitantes passou de 3,28 em 1960 para 3,65 em 1970 e para 5,13 em 1980, já sendo de 5,51 em 1982 6 . Em 2005, esteíndicesaltou para 20,37. N otaseum crescimento significativo do número de cirurgiões dentistas nas últimas duas décadas.

A Organização M undial deSaúderecomenda a relação de um dentista para cada 1.500 pessoas como uma relação adequada 7 . No Brasil, a relação encontra-se em torno de um cirurgião-dentista para cada 945 pessoas $^{7}$, que é explicado pelo aumento do número de cursos de odontologia em todo o país.

Em 1983, o número de cursos de odontologia no Brasil era de 66, graduando cerca de 5.200 novos cirurgiões-dentistas por ano. No campo da prestação de serviços, vigorava uma prática eminentementecurativa, com forte predominância do setor privado liberal e uma tímida intervenção do setor público e de planos privados de assistência odontológica. N essa época, 75\% das horas/dentista disponíveis estavam alocadas a atividades liberais ${ }^{6}$.

O Brasil passou de noventa cursos de odontologia ofer-tados em 1996 para 165 cursos em 2003. N esteperío-do, enquanto a população brasileira cresceu a uma proporção aproximada de 1,8\% ao ano, o crescimen-to do número de cirurgiões-dentistas foi de 2,5\% ao ano ${ }^{8}$.

Em 2005, existiam 173 faculdades deodontologia no país (27 federais, 18 estaduais, 7 municipais e 121 privadas) eum total de 203.713 dentistas - onze mil formados a cada ano, embora as 
barreiras de acesso aos serviços profissionais permaneçam as mesmas?.

\section{As restrições}

0 acesso aos serviços odontológicos no Brasil élimitado edesigual. Barros \& Bertoldi ${ }^{10}$ revelaram nível baixo de utilização de serviços odontológicos no Brasil ao investigar os dados da Pesquisa Nacional por Amostras de Domicílios (PNAD/IBGE, 1998). A proporção de $77 \%$ da população de até seis anos de idade jamais havia consultado um dentista. Na faixa etária entre 20 e 49 anos de idade, a proporção de pessoas que nunca consultaram dentista foi dezesseis vezes maior no grupo constituído pelos $20 \%$ mais pobres da população quando comparados com os $20 \%$ mais ricos. Entre a população idosa, a proporção de pessoas quenunca consultaram o dentista foi de $6,3 \%$ para o país, atingindo $50,7 \%$ na região Nordeste ${ }^{11}$.

Dados da PNAD (2003) mostram que uma parcela expressiva dos brasileiros $(15,9 \%)$ declarou nunca ter feito uma consulta ao dentista equivalente a 27,9 milhões de pessoas. Esta proporção era de $81,8 \%$ nos menores de 5 anos e $22,1 \%$ no grupo etário de 5 a 19 anos. Entre as pessoas com mais de 64 anos, 6,3\% nunca consultaram um dentista 3 .

A pesar desses indicadores, os dados do $\mathrm{Mi}$ nistério da Saúde revelam que a saúde bucal no Brasil vem recebendo uma parcela relativamente pequena em relação ao total de recursos repassados aos municípios. Em 2003, 1,63\% do investimento em saúde se destinavam aos procedimentos odontológicos. Estes valores não tiveram grandes alterações para o ano de $2005(1,47 \%)^{12}$. Os dados das despesas próprias de municípios e estados na são identificáveis ${ }^{13}$.

\section{Os gastos familiares residuais}

De acordo com dados da Pesquisa de Orçamento Familiar (POF), o gasto das famílias brasileiras com saúde representa o quarto maior grupo de dispêndios correntes, ficando atrás apenas das despesas com habitação, alimentação e transporte ${ }^{14}$. Para 2003, a média percentual de despesas totais das famílias brasileiras em assistência à saúde foi de 5,53\%, sendo de 0,54\% a proporção das despesas com consultas e tratamento dentário e 1,51\% com despesas com planos de saúde ${ }^{15}$. Ao comparar os gastos percentuais médios com consulta e tratamento dentário realizado pela POF de 1996 (1,19\%) e 2003 $(0,54 \%)$, observa-se um declínio relativo nos va- lores proporcionais ${ }^{16}$. Este fato pode estar associado à crisedo modelo liberal da profissão odontológica, já que essa redução relativa indica que, nestes cinco anos, o desembolso direto para a compra de serviços odontológicos diminuiu ${ }^{15,16}$.

Os gastos familiares com planos de saúde

Favaret \& Oliveira ${ }^{17}$ apresentaram a tese da universalização excludentecomo um possível efeito colateral da ampliação do acesso aos serviços públicos de saúde a partir da formação do Sistema Ú nico de Saúde (SUS), que passou a excluir progressivamente a classe média. A classe média buscou nos planos privados de assistência à saúde a solução de problemas de saúde. Esse fato foi potencializado pela oferta cada vez maior de planos de saúde para funcionários públicos e empregados do setor privado.

Apesar da maior parte das despesas com saúde ser destinada à compra de medicamentos, 0 pagamento de mensalidades de planos de saúde também tem peso relevante nas despesas familiares. 0 gasto com medicamentos e planos/seguro saúde representou respectivamente $40,6 \%$ e $28,2 \%$ das despesas com assistência à saúde das famílias brasileiras no ano de $2003^{15}$.

Em resumo, 0 aumento do número de profissionais dentistas, a maior concorrência por pacientes e a queda no desembolso direto, produzindo escassez depacientes no consultório particular, geram respostas estratégicas dos profissionais no formato de empresas cooperativas ou na criação das sociedades civis de natureza empresarial.

Estas respostas organizacionais aos processos estruturais justificam o estudo das empresas de odontologia de grupo e das cooperativas odontológicas. A hipótese central desse estudo éque estas modalidades empresariais representam duas estratégias organizacionais distintas para o setor. 0 formato organizacional afetaráo desempenho dessas empresas e sua posição futura no mercado. Cabe chamar atenção que existem outras modalidades para inserção dos serviços odontológicos no mercado de seguro, que serão assinalados a seguir.

\section{A dinâmica profissional e o mimetismo organização na formação \\ de empresas odontológicas}

As empresas odontológicas nas modalidades de cooperativa e de odontologia de grupo são de granderelevância no mercado de planos desaúde porque concentram a oferta do mercado de seguro em odontologia: estas modalidades somadas detêm $89,04 \%$ do número de beneficiários ${ }^{18}$. 
Observa-se uma alta concorrência no mercado de serviços profissionais de dentistas em al gumas regiões do país. Os profissionais procuram a solução no credenciamento a operadoras de planos odontológicos, como uma estratégia individual pela relação de trabalho assalariada ( no caso de operadoras com estrutura empresarial) ou corporativa por meio da vinculação a uma cooperativa. 0 dentista podeser remunerado via procedimento, via salário fixo por um período de trabal ho ou via pacotes de procedimentos.

Existem algumas opções para o profissional que decide ofertar seus serviços por meio de uma operadora de planos odontológicos. Ele pode optar entre a odontologia de grupo, cooperativa odontológica, autogestão, administradora de serviços, operadora de plano médico que também oferte o produto odontológico, bem como uma seguradora. Além de poder fazer a opção de se tornar parte da rede própria de uma operadora. Cabe ressaltar que existem critérios rígidos para o credenciamento ou a cooperação de um cirurgião-dentista a um plano de saúde ${ }^{19}$.

De acordo com dados de pesquisa do ConseIho Federal de O dontologia (2003), o total de profissionais dentistas inscritos no conselho era de 203.713. Esta pesquisa mostrou que $47,6 \%$ trabaIhavam com convênios e credenciamentos. Deste universo, 14,7\% participavam de algum tipo de cooperativa odontológica. Deste subconjunto, $65,6 \%$ estavam credenciados à Uniodonto 9 .

Observa-se, em resumo, que quase a metade dos profissionais dentistas está credenciada a algum tipo de plano de saúde odontológico, ressaltando-se que dentre as cooperativas odontológicas, a Uniodonto é a que apresenta maior número de profissionais credenciados.

Silva ${ }^{20}$ afirma que as cooperativas odontológicas se diferenciam das empresas de odontologia de grupo e das seguradoras especializadas em saúdena medida em quenão se constituem como empresas que são movidas apenas pela lucratividade e sim como entidades cuja propriedade é do conjunto dos trabal hadores cooperados. Dessa forma, a relação capital/trabalho dentro de uma cooperativa tende a ser oposta àquela que ocorre em uma empresa capitalista. $\mathrm{Na}$ empresa capitalista, o poder é exercido pelos detentores do capital (cada ação, um voto), que também se apropriam do excedente gerado; nas cooperativas, ao contrário, o processo decisório éexercido pelos próprios trabalhadores (cada trabalhador, um voto), responsáveis pela apropriação do excedentegerado.

Duarte ${ }^{21}$ destaca, reforçando esta tese, que, no segmento de saúde suplementar, "as coope- rativas são formalmente definidas como sociedades que se constituem para prestar serviços a seus associados, com vistas ao interesse comum e sem o objetivo de lucro".

Entre as cooperativas odontológicas, destacam-se as Uniodontos, que respondem pela quase totalidade das cooperativas que oferecem planos privados de assistência à saúde odontológica no Brasil. 0 sistema Uniodonto é formado por uma rede de empresas individuais que abrange todo o país.

As Uniodontos surgiram no Brasil, em 1972, em Santos (SP). Em março de 1993, o Sistema Uniodonto passou a se chamar Uniodonto do Brasil - Confederação Nacional das Cooperativas $\mathrm{O}$ dontológicas. Atualmente, a Uniodonto do Brasil conta com cerca de 170 Uniodontos singulares, quese organizam em noveFederações, sendo estas as Federações do Rio Grande do Sul, Paranaense, Paulista, da Região Norte, da Região Nordeste, do Rio de Janeiro e Espírito Santo, de Santa Catarina, de M inas Gerais e de Goiás e Tocantins. O Sistema Uniodonto possui atualmentecerca de vintemil cirurgiões-dentistas credenciados em todo o Brasil ${ }^{22}$.

Cada Uniodonto singular é uma cooperativa independente. Existeum sistema de repasse entre as cooperativas singulares que permite que um beneficiário possa ser atendido fora da cidadena qual adquiriu o plano odontológico. Cada cooperativa possui uma tabela própria para a remuneração de seus cooperados e o sistema Uniodonto como um todo conta com uma tabela única de repasse para remunerar esses casos ${ }^{19}$.

Diferentemente das cooperativas odontológicas, as empresas de odontologia de grupo podem fazer parte de grupo que opera plano médico-hospitalar ou pertencerem a um grupo empresarial específico para o setor odontológico, embora façam aliança comercial com operadoras de planos médico-hospitalares para expandirem posição no mercado.

A odontologia de grupo opera predominantemente em pré-pagamento, ou seja, as empresas recebem mensalidades regularmente, em vaIores fixos pré-estabelecidos, independente do valor dos tratamentos que o beneficiário venha a realizar. Quanto à comercialização, as operadoras trabalham tanto com corretores próprios, quanto com corretores terceirizados ${ }^{19}$.

Essas duas modalidades se consolidaram ao longo da década de 1990. A consolidação destas organizações é explicada pelos seguintes processos: a busca de rendas adicionais pela profissão odontológica associada ao baixo poder aquisitivo da população em custear tais serviços; com- 
petição dentro do setor produtivo, principalmente entre as empresas mais modernas; aumento dos custos dos serviços odontológicos, sobretudo os de maior densidade tecnológica; e a insatisfação da população com a oferta do SU S $^{1}$.

N esse contexto, baixas restrições institucionais limitaram o desenvolvimento das vertentes do cooperativismo ou do empresarialismo, predominando uma lógica de livre entrada no mercado para as soluções organizacionais.

Para analisar o formato organizacional e desempenho diferencial destas duas modalidades de planos de saúde odontológicos, este artigo assume como referência teórica os modelos organizacionais propostos por Di Maggio e Powell ${ }^{23}$.

Segundo Di Maggio e Powell ${ }^{23}$, as pressões institucionais propiciam adaptações organizacionais por meio de três mecanismos denominados processo mimético, isomorfismo normativo e isomorfismo coercitivo.

0 modelo mimético proposto pelos autores é referido às situações de incerteza que levam os agentes a adotar mecanismos organizacionais disponíveis no ambiente social. Nesse modelo, as organizações são modeladas em outras soluções já experimentadas com sucesso. $\mathrm{Na}$ experiência brasileira, quando houve a percepção sobre as mudanças estruturais do mercado de serviços odontológicos, uma das saídas adotadas foi a solução empresarial já provada no mercado de planos de saúde.

Powell \& DiM aggio ${ }^{23}$ afirmam que as organizações tendem a semoldarem a empresas similares em seu ramo com o objetivo de tornarem-se mais legítimas e suscetíveis. A ubiqüidade de al guns tipos de arranjos estruturais pode ser mais precisamente creditada a universalidade do processo mimético do que qualquer evidência concreta do que a eficiência aprimorada dos modelos adotado ${ }^{23}$. Esse é o caso da difusão no Brasil do modelo de empresas de odontologia de grupo que tiveram como antecessoras e inspiradoras as empresas de medicinas de grupo.

0 isomorfismo normativo tem origem na profissionalização. Os autores descrevem a profissionalização como o esforço coletivo de membros de uma ocupação em definir as condiçõese métodos de seus trabal hos, para controlar "a produção dos produtores" epara estabelecer uma base cognitiva e legiti mação para sua autonomia ocupacional.

Recentemente, o maior crescimento na profissão odontológica é de organizações profissionais, formando redes e criando um pool de indivíduos que ocupam posições similares, podendo moldar o comportamento organizacional. Este modelo influencia fortemente a criação das cooperativas odontológicas no mercado de planos de saúde.

0 isomorfismo coercivo éfortemente baseado na pressão formal einformal exercida em uma organização pela regulação de governo. Estas pressões podem ser percebidas por força ou como convites à cooperação com a regulação dos governos. Em algumas circunstâncias, a mudança organizacional é uma resposta direta de um mandato governamental. O regime de regulação, gerado pela criação da ANS em 2000, tem imposto um novo padrão institucional para a entrada, permanência e saída das empresas no mercado de planos de saúde no Brasil.

$O$ novo regime de regulação afeta a economia de escala e escopo das empresas operadoras pelo efeito seletivo das fortes barreiras institucionais à permanência, entrada e saída, bem como restringe a sobrevivência das empresas débeis quando aumenta as demandas sobre a qualidade da firma e limita a diferenciação de produto e aumenta os custos de transação pelo crescimento de despesas operacionais para manter a posição no mercado. 0 regime de regulação pode provocar importantes restrições ao padrão organizacional observado nas empresas de orientação empresarial e as cooperativas odontológicas, especialmente em relação à governança corporativa por força da pressão sobre a transparência informacional.

O esquema abaixo ilustra a aplicação do modelo de Powell \& DiM aggio ${ }^{23}$ às empresas de planos de saúde odontológicos.

\section{M etodologia}

Este trabalho desenvolve um estudo transversal e descritivo do arranjo organizacional e a análise quantitativa dos desempenhos operacionais efinanceiros das operadoras de planos de saúde odontológicos (cooperativa odontológica eodontologia de grupo). Para a análise exploratória, foram utilizados os dados do cadastro nacional de operadoras disponibilizado pela Agência $\mathrm{Na}$ cional de Saúde Suplementar.

A Agência Nacional de Saúde Suplementar (ANS) foi criada a partir da Lei no 9.961 de 28 de janeiro de 2000, vinculada ao M inistério da Saúde, como um órgão de regulação, normatização, controleefiscalização, em todo o território nacional, das atividades que garantam a assistência suplementar à saúde. Dessa forma, as ações relativas à estratégia de regulação do mercado brasileiro de saúde suplementar passaram a ser reali- 
Quadro 1. Mecanismo institucional e formato organizacional.

\begin{tabular}{|l|l|l|}
\hline Tipologia & Mecanismos & Formato organizacional \\
\hline Processos miméticos & $\begin{array}{l}\text { Empresas criadas sob ambiente de baixa } \\
\text { regulação que imitam condutas da } \\
\text { concorrência ou de outros setores }\end{array}$ & Odontologia de grupo \\
\hline Pressões normativas & Empresas criadas sob pressão das profissões & Cooperativas odontológicas \\
\hline Isomorfismo coercitivo & $\begin{array}{l}\text { Predomínio de governança corporativa } \\
\text { resultante da ação pública (regulação) }\end{array}$ & $\begin{array}{l}\text { Modelo de empresa pós- } \\
\text { regulação }\end{array}$ \\
\hline
\end{tabular}

zadas pela ANS, de modo a garantir a consecução dos objetivos básicos definidos pela nova legislação de regulamentação do setor:

- Assegurar aos consumidores de planos privados de assistência à saúde cobertura assistencial integral e regular as condições de acesso;

- Definir e controlar as condições deingresso, operação e saída das empresas e entidades que operam no setor;

- D efinir eimplantar mecanismos de garantias assistenciais e financeiras, das operadoras e do sistema, que assegurem a continuidade da prestação de serviços à saúde contratados pelos consumidores;

. Dar transparência e garantir tanto a integração do setor de saúde suplementar ao SUS como que o sistema seja ressarcido quanto aos gastos gerados pelos consumidores de planos privados de assistência à saúde;

. Estabelecer uma política de regulação depreços, definindo mecanismos de controle capazes de coibir possíveis abusos de preço; e

- Definir o sistema de regulamentação, normatização e fiscalização do setor saúde suplementar, buscando o funcionamento equilibrado do sistema e do próprio modelo de regulação e de fiscalização ${ }^{24}$.

Deacordo com o Artigo 30 da Lei no 9.961/00, a finalidade institucional da ANS é promover a defesa do interesse público na assi stência suplementar à saúde, regulando as operadoras setoriais, inclusive quanto às suas relações com prestadores e consumidores, contribuindo para o desenvolvimento das ações de saúdeno país. Desta maneira, a ANS foi instituída para unificar todas as funções de regulação do setor de saúde suplementar, tanto em seu aspecto assistencial quanto em sua dimensão econômico financeira ${ }^{24}$.

Um exemplo importante das mudanças introduzidas pela lei foi a instituição da obrigatoriedade de informações. Isso permite à ANS promover diversas análises e, em especial, acompanhar a evolução dos custos, condição essencial para a autorização de aumento das mensalidades dos planos individuais ${ }^{24}$.

Determinadas características, como a modalidade da contratação, a data da assinatura, a cobertura assistencial e a abrangência geográfica, submetem os contratos de forma diferenciada à legislação.

O cadastro de operadoras disponibilizado pela ANS constitui um banco de dados de informações da saúde suplementar, que discrimina as demonstrações contábeis das operadoras em pequeno (até4.999 beneficiários), médio (de5.000 à 19.999 ben eficiários) e grande porte (acima de 20.000 ben eficiários). A partir destecadastro, têmse os dados econômicos financeiros das operadoras de planos de saúde.

0 estudo transversal é o estudo no qual uma ou mais variáveis são coletadas em um mesmo período, como, por exemplo, o censo populacional conduzido a cada dez anos ${ }^{25}$.

0 estudo transversal considerou todas as operadoras das categorias Cooperativa O dontológica e Odontologia de Grupo inseridas no banco de dados da ANS.

As variáveis dependentes extraídas do cadastro contábil da ANS foram: a receita total 2002, receita total 2004, despesas 2004, despesas de comercialização 2004, despesas administrativas 2004, receita financeira líquida 2004, patrimônio líquido 2004 e resultado líquido 2004. Para investigar a eficiência financeira das operadoras, foram utilizados indicadores econômicos financeiros, tais como rentabilidadeeíndicededespesa assistencial. A utilização destes indicadores proporcionou a análise do padrão econômico financeiro das empresas, bem como a comparação dos desempen hos operacionais das duas modalidades de operadoras estudadas.

Rodrigue ${ }^{26}$ definerentabilidadecomo o ganho que a empresa obtém do seu esforço produtivo, essencial para que ela possa remunerar os fatores de produção econtinuar seu ciclo de operações. Colocando nestes termos, podemos di- 
zer que o sucesso ou o insucesso da empresa está associado a sua rentabilidade.

A rentabilidade representa o quanto a empresa obteve delucro para cada $\mathrm{R} \$ 1,00$ de capital próprio investido e é calculada a partir da razão entre o resultado líquido e o patrimônio líquido médio.

Esse indicador representa a taxa de rentabilidade do capital investido pelos sócios da operadora e a interpretação do indicador é do tipo quanto maior, melhor ${ }^{27}$.

M étodo decálculo: I rentab. $=\frac{\text { resultado líquido } \times 100}{\text { patrimônio líquido }}$

0 índice de despesa assistencial refere-se ao quanto a operadora incorreu em despesas assistenciais expressas na forma de eventos indesejáveis em relação ao faturamento da operadora. Este faturamento é relativo ao total de receita ganha em função da contratação dos serviços de assistência à saúde por parte dos beneficiários. É o principal índice de custo da operadora ${ }^{27}$.

Em termos financeiros, quanto menor esse indicador, melhor éa situação financei ra da operadora.

M étodo de cálculo: $\mid=\frac{\text { despesa assistencial }}{\text { receita }} \times 100$

Foram também utilizadas, como variáveis dependentes, o porte, considerando o número de beneficiários, e a localização geográfica. A hipótese central do estudo é que estas variáveis apresentam comportamentos idênticos, independente do modelo organizacional da modalidade de plano odontológico ser do tipo empresarial ou cooperativo. A tipologia proposta por DiM aggio e Powell ${ }^{23}$ será tomada, portanto, como a variável independente.

Os dados obtidos a partir do banco foram tabulados em planilhas Excel e explicados estatisticamente por meio de descrição etestes analíticos com o auxílio de programas estatísticos.

\section{Resultados}

Após vigência do regime de regulação instituído pela Lei n 9.656/98 e pela criação da ANS, o número de beneficiários por operadora de serviços exclusivamente odontológicos teve um aumento considerável tanto para a odontologia de grupo (252\%) quanto para as cooperativas odontológicas (205\%), retratando um rápido crescimen- to de mercado (Tabela 1). A oferta de planos odontológicos nas modalidades Seguradora Especializada, Autogestão eCooperativa M édica teve nesse processo um crescimento muito expressivo, embora permaneça com uma participação residual no mercado. Já a modalidade Filantropia apresentou um decréscimo no número de beneficiários no período. É possível considerar, como jámencionado, quea ineficiência de oferta do serviço público e a eficiência do setor de planos de saúde, propiciada pela competição, possam estar explicando este processo ${ }^{28}$.

0 mercado de planos de saúde odontológico tem apresentado, portanto, um grande dinamismo na geração de receitas nos anos recentes no Brasil. As cooperativas odontológicas tiveram um crescimento de receita de $150 \%$ e a odontologia degrupo, de 168,5\% entre os anos de2002 e 2004. Esse dinamismo é resultado de estratégias empresarias dos profissionais dentistas e das mudanças nas condições de financiamento da atenção odontológica.

A análise transversal sobre os dois modelos organizacionais mostrou que o mercado de planos de saúde odontológico é pulverizado com o predomínio de pequenas empresas ( Tabela 2).

A região Sudeste concentra o maior número de empresas cooperativas (58\%) e de odontologia de grupo (59,2\%), onde o estado de São Paulo é o mais expressivo (62,5\% e 77,8\%, respectivamente).

0 perfil de distribuição do total de beneficiários, receita, despesas e patrimônio líquido não apresentou diferença estatisticamentesignificante entre as duas categorias empresariais estudadas globalmente.

Existe uma forte correlação entre o número de beneficiários e receita de 2004, tanto para as cooperativas ( $R=0,62 ; p<0,01)$, quanto para a odontologia de grupo $(R=0,373 ; p<0,01)$. Este padrão é também observado na despesa de 2004 (respectivamente: $\mathrm{R}=0,618 ; \mathrm{p}<0,01$ / $\mathrm{R}=0,373$; $p<0,01)$, que mostra associação estatisticamente significante com o número de beneficiários.

Pela Tabela 3, observa-se que a variação marginal para receita nascooperativaséde $\$$ 190,00 a cada aumento de $1 \%$ no número de beneficiários e, para a odontologia de grupo, este valor é de $\mathrm{R} \$ 111,00$. Em relação às despesas totais, a variação marginal nas cooperativasé de R \$195,00 a cada aumento de $1 \%$ no número de beneficiáriose, na odontologia de grupo, é de $\mathrm{R} \$ 80,00$.

Nota-se que a variação marginal das despesas é maior do que o das receitas nas cooperativas em 2004. À medida que aumenta o número debeneficiários, ecresce a receita arrecadada pela 
Tabela 1. Beneficiários por modalidade da operadora e vigência do plano.

\begin{tabular}{lrrrrr}
\hline \multicolumn{1}{c}{ Modalidade } & \multicolumn{2}{c}{$\begin{array}{c}\text { Antigos (anteriores } \\
\text { à Lei } \mathrm{n}^{\circ} \text { 9.656/98) }\end{array}$} & $\begin{array}{c}\text { Novos (posteriores } \\
\text { à Lei } \mathrm{n}^{\circ} \text { 9.656/98) }\end{array}$ & $\begin{array}{c}\text { Porcentagem } \\
\text { de crescimento }\end{array}$ \\
\hline Odontologia de grupo & 1.065 .257 & $28,4 \%$ & 2.687 .430 & $71,6 \%$ & $252 \%$ \\
Cooperativa odontológica & 486.948 & $32,8 \%$ & 998.717 & $67,2 \%$ & $205 \%$ \\
M edicina de grupo & 105.555 & $28,8 \%$ & 260.911 & $71,2 \%$ & $247 \%$ \\
Seguradora especializada em saúde & 4.173 & $1,7 \%$ & 239.252 & $98,3 \%$ & $573 \%$ \\
Autogestão & 4.508 & $21,0 \%$ & 16.973 & $79,0 \%$ & $377 \%$ \\
Cooperativa médica & 1.577 & $18,2 \%$ & 7.070 & $81,8 \%$ & $448 \%$ \\
Filantropia & 3.100 & $69,5 \%$ & 1.360 & $30,5 \%$ & $44 \%$ \\
Total & 1.671 .118 & $28,4 \%$ & 4.211 .713 & $71,6 \%$ & $252 \%$ \\
\hline
\end{tabular}

Fonte: Cadastro de operadoras e beneficiários da $\mathrm{ANS}^{18}$.

\begin{tabular}{lrrrrrr}
\hline \multicolumn{2}{l}{ Tabela 2. Relação entre número de beneficiários e operadoras de planos odontológicos. } \\
\hline \multicolumn{1}{c}{ Porte } & Cooperativas odontológicas & Odontologia de grupo & \multicolumn{2}{c}{ Total } \\
\hline Pequeno & 87 & $66,9 \%$ & 183 & $71,2 \%$ & 270 & $69,8 \%$ \\
Médio & 35 & $26,9 \%$ & 47 & $18,3 \%$ & 82 & $21,2 \%$ \\
Grande & 8 & $6,2 \%$ & 27 & $10,5 \%$ & 35 & $9 \%$ \\
Total & 130 & $100 \%$ & 257 & $100 \%$ & 387 & $100 \%$ \\
\hline
\end{tabular}

Tabela 3. Variação marginal das receitas e despesas das modalidades.

\begin{tabular}{lcc}
\hline & $\begin{array}{c}\text { Odontologia } \\
\text { de grupo }\end{array}$ & $\begin{array}{c}\text { Cooperativas } \\
\text { odontológicas }\end{array}$ \\
\hline Receitas & $R \$ 111,00$ & $R \$ 190,00$ \\
Despesas & $R \$ 80,00$ & $R \$ 195,00$ \\
Diferença & $R \$ 31,00$ & $-R \$ 5,00$ \\
\hline
\end{tabular}

operadora, a despesa se eleva em uma proporção maior do que a receita.

Esse comportamento pode ser explicado pela evidência que as duas modalidades apresentam padrões muito diferenciados de desempenho econômico financeiro. As cooperativas odontológicas possuem despesas assistenciais el evadas. Cerca de $70 \%$ das despesas totais das cooperativas são relacionadas às despesas assistenciais. Este padrão por porte é significativamente homogêneo, não importando o porte da cooperativa. A odontologia de grupo apresenta despesas assistenciais inferiores às cooperativas. Cerca de 50\% em média das despesas totais são destinadas aos gastos assistenciais. A organização empresarial (odontologia de grupo), por ter uma gestão mo- delada pelo mecanismo de empresa, tende a ter despesas com assistenciais menores. Já a cooperativa, por estar associada à força de coalizão profissional, aparentemente a redistribuição das receitas entre os associados é elevada ou os custos da assistência prestada são elevados em função da maior qualidade ou baixo controle dos custos. Q uando analisadas pelo controle do porte, as empresas estudadas apresentaram diferença no padrão derentabilidadeem relação ao porte. As cooperativas demonstram um aumento da rentabilidade inversamente proporcional ao aumento do número de beneficiários.

As empresas de modalidade O dontologia de grupo não apresentam este padrão. As empresas de médio porte são as mais rentáveis. As de pequeno porte são também exuberantes na rentabilidade; entretanto, nas maiores empresas é observada menor heterogeneidade na rentabilidade. Elas são também muito eficientes (Tabela 4).

As empresas de pequeno porte, para a modalidade Odontologia de grupo, apesar de possuírem elevada rentabilidade, apresentam uma maior proporção de empresas com rentabilidade negativa $(23,5 \%)$, enquanto que nenhuma operadora de grande porte mostrou rentabilidade negativa (Tabela 5). 
Tabela 4. Rentabilidade segundo os padrões organizacionais.

\begin{tabular}{|c|c|c|c|c|c|c|}
\hline \multirow{2}{*}{ Porte } & \multicolumn{3}{|c|}{ Odontologia de grupo } & \multicolumn{3}{|c|}{ Cooperativa odontológica } \\
\hline & M ediana & M édia & Coeficiente de variação & M ediana & M édia & Coeficiente de variação \\
\hline Pequeno & $37,2 \%$ & $145,8 \%$ & $310 \%$ & $26,3 \%$ & $104,6 \%$ & $260 \%$ \\
\hline M édio & $76,4 \%$ & $152,0 \%$ & $200 \%$ & $15,2 \%$ & $34,0 \%$ & $230 \%$ \\
\hline Grande & $51,7 \%$ & $67,3 \%$ & $90 \%$ & $29,0 \%$ & $30,2 \%$ & $70 \%$ \\
\hline
\end{tabular}

Tabela 5. Distribuição proporcional de rentabilidade negativa e positiva segundo os padrões organizacionais.

\begin{tabular}{lcccccccc}
\hline \multirow{2}{*}{ Porte } & \multicolumn{3}{c}{ Odontologia de grupo } & & & \multicolumn{2}{c}{ Cooperativa odontológica } \\
\cline { 2 - 4 } \cline { 7 - 8 } & Negativa & Positiva & N/P & & N egativa & Positiva & N/P \\
\hline Pequeno & 28 & 91 & $23,5 \%$ & & 21 & 50 & $30 \%$ \\
M édio & 4 & 33 & $11 \%$ & & 7 & 26 & $21 \%$ \\
Grande & - & 25 & - & & - & 6 & - \\
\hline
\end{tabular}

\section{Conclusões}

A análise geral do desempenho do setor de planos odontológicos revela impressionante dinamismo na captação de clientes, mesmo após a criação da ANS. Esse dinamismo é resultado de estratégias empresarias e da ação coletiva dos profissionais dentistas, motivadas por mudanças nas condições de financiamento da atenção odontológica.

Estes dados evidenciam que o setor de planos de saúde odontológicos é altamente rentável, apresentando uma grande capacidade na geração de receitas que pode favorecer o crescimento e a permanência destas empresas no mercado. Os padrões de rentabilidade média, principalmente das empresas de odontologia de grupo, são extremamente elevados, ficando muito acima de qualquer atividade deste segmento empresarial do país.

A rentabilidade das cooperativas de pequeno porte étambém muito significativa. As cooperativas de médio e grande porte apresentam um padrão médio de rentabilidade ligeiramente inferior, porém ainda assim invejável dentro dos padrões empresariais brasileiros.

Porém, as empresas de modalidade cooperativa demédio e grande porte oferecem uma solução organizacional muito vantajosa para a estratégia corporativa da profissão odontológica, pois apresentam um padrão de despesa com assistência muito superior ao observado na odontologia degrupo. É possível quegrande partedessas despesas assistenciais seja destinada à remuneração do profissional vinculado à cooperativa ou possa estar refletindo a qualidade dos serviços oferecidos pela modalidade. Ou, ainda, as elevadas despesas assistenciais sejam resultantes da falta de controle sobre os custos operacionais. Os dados não permitem identificar com clareza a natureza dessa destinação de recursos. As empresas de odontologia de grupo apresentam, por outro lado, maior eficiência e uma perspectiva de sustentabilidade empresarial porque suas receitas variam positivamente marginalmente acima das despesas em relação direta com o tamanho da empresa. 0 contrário éobservado nas cooperativas odontológicas.

0 modelo deanálise de Di M aggio ePowell ${ }^{23}$, baseado nos mecanismos mimético e normativo profissional, foi satisfatório para explicar o desempenho diferenciado dos diferentes arranjos organizacionaisidentificadosno mercado de planos de saúde odontológicos. Resta saber o quanto pressões coercitivas originadas pelo regime de regulação afetarão esses arranjos. Principalmente no que tange ao risco de baixa sustentabilidade identificado na relação despesa/receita nas empresas de maior porteno modelo de cooperativa. Esterisco é explicado, no estudo com dados transversais, pelo elevado padrão de remuneração destas empresas com atividades assistenciais. Isto pode reforçar a possibilidade de que esta modalidade deverá se adaptar aos novos padrões de governança corporativa definidos pela ANS. N essa hipótese, teríamos uma clara mudança no padrão organizacional das cooperativas por força de mecanismos coercitivos. N ovos dados devem ser analisados para verificar se essas evidências permanecem válidas para a explicação do 
comportamento econômico financeiro dessas modalidades organizacionais do mercado de planos de saúde odontológicos.

\section{Colaboradores}

C Vieira trabalhou na coleta dos dados, revisão bibliográfica, elaboração e redação final do texto. NR Costa participou da revisão bibliográfica, elaboração e redação final do texto.

\section{Referências}

1. Costa NR, Castro AJW. O regime regulatório e a estrutura do mercado de planos de assistência a saúde no Brasil. In: Montone J, Castro AJW, organizadores. Documentos técnicos de apoio ao fórum de saúde suplementar de 2003. Vol.3. Tomo1. Rio de Janeiro: ANS; 2004. p. 49-64.

2. Montone J. A regulamentação do setor de saúde suplementar. In: Agência Nacional de Saúde Suplementar. 0 impacto da regulamentação no setor de saúde suplementar. Rio de Janeiro: ANS; 2000. p. 7-37.

3. Instituto Brasileiro de Geografia e Estatística. Pesquisa Nacional por Amostra de Domicílios. Acesso e utilização de serviços de saúde: IBGE; 2003. [acessado $2005 \mathrm{M}$ ai 15]. Disponível em: http://www. ibge.gov.br

4. Cienc Saude Colet [periódico na internet]. 2006 [acessado 2006 Jul 12]; 11(1). Disponível em: http://www. scielo.br/scielo.php?script=sci issuetoc $\&$ pid $=1413$ $-812320060001 \& \operatorname{lng}=p t \& n r m=\bar{i}$ so

5. Silveira JLGC, Oliveira V. Experiência e expectativas dos cirurgiões-dentistas com os planos de saúde. Rev Pesq Bras O dontoped Clin Integr 2002; 2(1):30-36

6. Pinto VG. Saúde bucal no Brasil. Rev. Saúde Pública 1983; 17:316-327.

7. Mendes HJ. A relação entre cirurgiões-dentistas e as operadoras de planos de saúde no município de Bauru - SP [dissertação]. Bauru (SP): Faculdade de Odontologia de Bauru; 2005.

8. M oysés SJ. Políticas de saúde e formação de recursos humanos em Odontologia. Rev ABENO 2004; 4(1):30-37.

9. Conselho Federal de Odontologia. Perfil do Cirurgião dentista: CFO, 2003. [acessado 2005 Jan 10]. Disponível em: http://www.cfo.org.br

10. Barros AJD, Bertoldi AD. Desigualdades na utilização e no acesso a serviços odontológicos: uma avaliação em nível nacional. Cien Saude Colet 2002; 7(4):709-717.

11. Matos DL, Giatti L, Lima-Costa M F. Fatores sóciodemográficos associados ao uso de serviços odontológicos entre idosos brasileiros: um estudo baseado na Pesquisa Nacional por Amostras de Domicílios. Cad Saúde Pública 2004; 20(5):1290-1297.

12. Brasil. Datasus. Informações Financeiras. [acessado 2006 Jul 24]. Disponível em: http://portal. saude.gov.br/portal/aplicacoes/transferencias/ regiao. $\mathrm{cfm}$ ? regiao $=9$

13. Brasil. Sistema de Informações sobre Orçamento Público em Saúde (SIOPS). Datasus: 2006. [acessado 2006 Jul 24]. Disponível em: http://siops.datasus.gov.br

14. Silveira FG, Osório RG, Piola SF. Os gastos das famílias com saúde. Cien Saude Colet 2002; 7(4):719-731.

15. Instituto Brasileiro de Geografia e Estatística. Pesquisa Orçamentária Familiar: IBGE; 2003. [acessado 2006 M ai 17]. Disponível em: http://www.sidra. ibge.gov.br

16. Instituto Brasileiro de Geografia e Estatística. Pesquisa Orçamentária Familiar: IBGE; 1996. [acessado 2006 mai 17]. Disponível em: http://www.sidra. igbe.gov.br

17. Favaret Filho P, Oliveira PJ. A universalização excludente: reflexões sobre as tendências do sistema de saúde. Dados Rev Ciências Sociais 1990; 33(2):257-283.

18. Agência Nacional de Saúde Suplementar. Caderno de Informação da Saúde Suplementar: beneficiáriOS, operadoras e planos: ANS; 2005. [acessado 2005 Mai 13]. Disponível em: http://www.ans.gov.br

19. Agência Nacional de Saúde Suplementar. Regulação e saúde: Planos Odontológicos: uma abordagem econômica no contexto regulatório. Rio de Janeiro: ANS; 2002.

20. Silva HP. Regulação econômica do mercado de saúde suplementar no Brasil [dissertação]. Campinas (SP): UNICAMP; 2003.

21. Duarte C. A assistência médica suplementar no Brasil: história e características da cooperativa de trabalho médico Unimed. In: Braga JCS, Silva PLB. Brasil: radiografia da saúde. Campinas: UNICAMP; 2001. p. 363-393.

22. Uniodonto. [acessado 2005 Set 20]. Disponível em: http://www.uniodonto.com.br

23. Di Maggio PJ, Powell WW. The iron cage revisited: Institutional isomorphism and collective rationality in organization fields. In: Di Maggio PJ, Powell WW, editors. The New Institutionalism in Organizational Analysis. Chicago: The University of Chicago Press; 1991. p. 63-82.

24. Agência Nacional de Saúde Suplementar. Lei n 9.961 de 28 de janeiro de 2000. ANS; 2000. [acessado 2005 mai 15]. Disponível em: http://www.ans.gov.br

25. Gujarati DN. Basic Econometrics. New York: M cGraw-Hill; 2003.

26. Rodrigues IPF. Tecnologia, organização e rentabilidade: um modelo para investigação empírica. Rev Administração de Empresas 1984; 24(4):63-60.

27. Agência Nacional de Saúde Suplementar. IDSS Qualificação da saúde suplementar: Indicadores Econômico-Financeiros. ANS; 2006. [acessado 2006 Mai 08]. Disponível em: http://www.ans.gov.br/ portal/site/informacoesss/informacoesss.asp

28. Agência Nacional de Saúde Suplementar. Caderno de Informação da Saúde Suplementar. AN S; 2005. [acessado 2006 Jun 10]. Disponível em: http:// www.ans.gov.br

Artigo apresentado em 04/10/2006

Aprovado em 02/04//2007

Versão final apresentada em 30/04/2007 